\title{
Recent Advances in Simulation for Pediatric Critical Care Medicine
}

\author{
Ilana Harwayne-Gidansky ${ }^{1}$ (i) $\cdot$ Rahul Panesar $^{1} \cdot$ Tensing Maa ${ }^{2}$
}

Published online: 28 August 2020

(C) Springer Science+Business Media, LLC, part of Springer Nature 2020

\begin{abstract}
Purpose of Review This review highlights the emerging fields of simulation research by tying innovation into principles of learning and process improvement.

Recent Findings Advances have been made in both educational simulation and simulation for quality improvement, allowing this versatile modality to be more broadly applied to healthcare and systems.

Summary Simulation in pediatric critical care medicine continues to evolve. Although the majority of simulation is focused on learner education, emerging research has broadened to focus on patient- and system-centered outcomes, leading to improvement in the quality of care delivered in the ICU.
\end{abstract}

Keywords Healthcare simulation · Pediatric critical care medicine $\cdot$ Medical education $\cdot$ Quality and patient safety

\section{Introduction}

Simulation is defined as "an instructional process that substitutes real patient encounters with artificial models, live actors or virtual reality patients" (Table 1) [1]. This modality has been used in industries other than medicine such as aviation, for decades, wherein adequate training is vital for critical events that are high risk, low frequency, and costly, whether in economic or health-related currency. This review provides a brief theoretical background of simulation-based medical education (SBME) and then highlights research with translational implications to pediatric critical care medicine (PCCM) for education and training, evaluation and maintenance of skills, advancement of quality healthcare delivery, and patient safety (Table 2).

This article is part of the Topical Collection on Intensive Care Medicine

Ilana Harwayne-Gidansky

ilana.harwayne-gidansky@ stonybrookmedicine.edu

1 Division of Critical Care, Stony Brook Children's Hospital, Renaissance School of Medicine, Stony Brook, NY, USA

2 Division of Pediatric Critical Care Medicine, Nationwide Children's Hospital, Ohio State University College of Medicine, Columbus, OH, USA

\section{History of Simulation-Based Medical Education}

In 1967, engineer S. Abrahamson and anesthesiologist J. Denson at the University of Southern California built and demonstrated the first computer-controlled patient simulator, "Sim One" [2, 3]. This was an interactive mannequin that could be intubated, and which responded to interventions and medications with appropriate vital sign changes. Anesthesia residents who trained on Sim One showed improved performance, as compared with conventional training methods. Despite this promising start, medical simulation would not be taken seriously until almost 20 years later, after the 1999 Institute of Medicine (IOM) report, "To Err is Human" [4], highlighted the recurrent types of errors leading to preventable patients deaths: diagnostic errors, treatment errors, preventive errors, and most often, communication errors at a systems level [5].

\section{Components of Simulation}

There are three major components to healthcare simulation in the PICU: the prebriefing, the simulation, and the debriefing. Prebriefing is an important component of healthcare simulation as it sets the stage for a scenario, and assists participants in 
Table 1 Specific terms used in this article

\begin{tabular}{|c|c|c|}
\hline Term & Definition & References \\
\hline Simulation & $\begin{array}{l}\text { "An instructional process that substitutes real patient encounters with artificial models, live actors } \\
\text { or virtual reality patients". }\end{array}$ & $\begin{array}{l}\text { Gaba et al., } \\
\quad 2004\end{array}$ \\
\hline Prebriefing & $\begin{array}{l}\text { "An information or orientation session held prior to the start of a simulation activity in which instructions } \\
\text { or preparatory information is given to the participants. The purpose of the prebriefing is to set the stage } \\
\text { for a scenario, and assist participants in achieving scenario objectives". }\end{array}$ & $\begin{array}{l}\text { Lioce et al., } \\
2020\end{array}$ \\
\hline Debriefing & $\begin{array}{l}\text { The point where participants can process, react to, reflect on, and analyze their actions, thoughts, and } \\
\text { feelings to close performance gaps. }\end{array}$ & $\begin{array}{l}\text { Rudolph et al., } \\
\quad 2008\end{array}$ \\
\hline Moulage & $\begin{array}{l}\text { "The makeup and molds applied to humans or manikins used to portray lesions, skin findings, bleeding, } \\
\text { and traumatized areas". }\end{array}$ & $\begin{array}{l}\text { Levine et al., } \\
2013 \\
\text { Lioce et al., } \\
2020\end{array}$ \\
\hline Mastery learning & $\begin{array}{l}\text { Learning with an eye towards achieving full competency; often taught through deliberate practice of } \\
\text { feedback and correction. }\end{array}$ & $\begin{array}{l}\text { McGaghie et al., } \\
2015\end{array}$ \\
\hline Functional fidelity & The ability of the simulated equipment to function and respond as it would in reality. & $\begin{array}{l}\text { Lioce et al., } \\
\quad 2020\end{array}$ \\
\hline Physical fidelity & "The degree to which the simulation looks, sounds, and feels like the actual task". & $\begin{array}{l}\text { Alexander et al., } \\
2005 \\
\text { Lioce et al., } \\
\quad 2020\end{array}$ \\
\hline Psychological fidelity & The ability of the simulation to induce a psychological response in its participants. & $\begin{array}{l}\text { Dieckmann } \\
\text { et al., } 2008\end{array}$ \\
\hline Translational simulation & $\begin{array}{l}\text { "A functional term for how simulation may be connected directly with health service priorities and patient } \\
\text { outcomes, through interventional and diagnostic functions, independent of the location of the simulation } \\
\text { activity" }\end{array}$ & Brazil 2017 \\
\hline Directive feedback & Feedback given with the 'intent of improving future performance'. & $\begin{array}{l}\text { Sawyer et al., } \\
2016 \\
\text { Eppich et al., } \\
2015\end{array}$ \\
\hline $\begin{array}{l}\text { Rapid cycle deliberate } \\
\text { practice }\end{array}$ & $\begin{array}{l}\text { Directive feedback that is given in a rapid and iterative manner to quickly acquire procedural and } \\
\text { teamwork skills. }\end{array}$ & Hunt et al., 2014 \\
\hline Plus-delta & $\begin{array}{l}\text { Point-counterpoint method whereby debriefing is focused on what went well and what could be change } \\
\text { or improve upon in the future }\end{array}$ & $\begin{array}{l}\text { Fanning et al., } \\
2007 \\
\text { Eppich et al., } \\
2015\end{array}$ \\
\hline Advocacy-inquiry & Inquiry into a learner's rationale for behavior while advocating for the patient's perspective. & $\begin{array}{l}\text { Eppich et al., } \\
2015\end{array}$ \\
\hline $\begin{array}{l}\text { Debriefing with good } \\
\text { judgment }\end{array}$ & Allows for contextual learning and change by understanding a learner's frames. & $\begin{array}{l}\text { Rudolph et al., } \\
2007\end{array}$ \\
\hline $\begin{array}{l}\text { Debriefing for } \\
\text { meaningful learning }\end{array}$ & $\begin{array}{l}\text { "The integration, assimilation or construction and transfer of prior cognitive knowledge with new } \\
\text { conceptual knowledge". }\end{array}$ & $\begin{array}{l}\text { Dreifuerst et al., } \\
2011 \\
\text { Schweitzer, } \\
2008\end{array}$ \\
\hline PEARLS & Promoting Excellence and Reflective Learning in Simulation - Scripted debriefing framework. & $\begin{array}{l}\text { Eppich et al., } \\
2015\end{array}$ \\
\hline
\end{tabular}

achieving scenario objectives" [6]. This, in turn, facilitates a focus of psychological safety of the learners and sets the tone for the simulation [7]. It is defined as, "An information or orientation session held prior to the start of a simulation activity in which instructions or preparatory information is given to the participants. Debriefing, or facilitated feedback, represents the point where participants can process, react to, reflect on, and analyze their actions, thoughts, and feelings to close performance gaps [8]. Using directive feedback with either individual or small group sessions has been shown to be efficacious, especially for highly technical, task-based skills [9]. Best practices in debriefing exist and a variety of methods have been described including directive feedback, plus-delta, advocacy-inquiry, debriefing with good judgment or 
Table 2 Illustrative examples of using simulation to achieve translational outcomes

\begin{tabular}{|c|c|c|c|c|}
\hline \multicolumn{2}{|c|}{ Simulation Topic } & \multirow{2}{*}{$\begin{array}{l}\text { Study } \\
\text { Kessler et al., } 2015\end{array}$} & \multirow{2}{*}{$\begin{array}{l}\text { Importance } \\
\text {-Translating simulation to success with infant lumbar puncture }\end{array}$} & \multirow{2}{*}{$\begin{array}{l}\text { Translation } \\
\text { level }\end{array}$} \\
\hline Teaching & Task & & & \\
\hline and & training & Tofil et al., 2018 & -Educating parents on tracheostomy care prior to discharge home & $\mathrm{T} 1$ \\
\hline \multirow[t]{9}{*}{ Learning } & & $\begin{array}{l}\text { Barsuk 2009, Cohen } \\
2010\end{array}$ & -Central venous line training improves patient outcomes including complications & $\mathrm{T} 2, \mathrm{~T} 3$ \\
\hline & Mock & Hunt et al., 2014 & -Rapid Cycle Deliberate Practice (RCDP) educational model improves CPR skills & $\mathrm{T} 1$ \\
\hline & Codes & Andreatta et al., 2011 & -Simulated mock codes improve pediatric patient cardiopulmonary arrest survival & $\mathrm{T} 3$ \\
\hline & & & $\begin{array}{l}\text { rates } \\
\text { •"Rolling Refresher" training improves retention of chest compression psychomotor }\end{array}$ & \\
\hline & Team & Colman et al. 2019 & -Simulation-based team training improves behaviors and skills associated with patient & $\mathrm{T} 1$ \\
\hline & Training & Sawyer et al. 2019 & $\begin{array}{l}\text { survival } \\
\text {-Pediatric Extracorporeal Cardiopulmonary Resuscitation (ECPR) simulation training } \\
\text { improves behaviors, protocol compliance, and activation time }\end{array}$ & $\mathrm{T} 1, \mathrm{~T} 2$ \\
\hline & Virtual & Badke et al. 2019 & -Virtual Reality for patients improves subjective experiences in the PICU & $\mathrm{T} 1$ \\
\hline & reality & Zackoff et al. 2020 & $\begin{array}{l}\text {-Impact of an immersive virtual reality curriculum on medical students' clinical } \\
\text { assessment of infants with respiratory distress }\end{array}$ & $\mathrm{T} 1$ \\
\hline & $\begin{array}{l}\text { Boot } \\
\text { Camps }\end{array}$ & Nishisaki et al. 2009 & -Boot camp is effective and subjectively valuable for learning basic PICU fellow skills & $\mathrm{T} 1$ \\
\hline \multirow{3}{*}{\multicolumn{2}{|c|}{ Patient safety and systems }} & Harwayne-Gidansky & -Using "Mirror patients" during simulation training helps identify latent safety threats & $\mathrm{T} 3$ \\
\hline & & et al. 2019 & -Simulating anaphylaxis events helps uncover common latent safety threats & $\mathrm{T} 3$ \\
\hline & & Maa et al. 2019 & & \\
\hline \multirow{3}{*}{\multicolumn{2}{|c|}{ Assessment }} & Calhoun et al. 2018 & -The International Simulation Data Registry captures CPR quality metrics on & $\mathrm{T} 1$ \\
\hline & & Faudeux et al. 2017 & simulated patients from multiple institutions & $\mathrm{T} 1$ \\
\hline & & & -A resuscitation checklist helps to evaluate technical resuscitation skills & \\
\hline \multirow{3}{*}{\multicolumn{2}{|c|}{ Debriefing }} & Dube et al. 2019 & -Promoting Excellence and Reflective Learning in Simulation (PEARLS) & $\mathrm{T} 3$ \\
\hline & & Bajaj et al. 2018 & -A debriefing tool focusing on systems-based simulations & \\
\hline & & Eppich et al. 2015 & $\begin{array}{l}\text {-A healthcare debriefing tool } \\
\text {-A debriefing framework }\end{array}$ & \\
\hline \multirow{2}{*}{\multicolumn{2}{|c|}{ Research Networks }} & Cheng et al. 2018 & -The INSPIRE network & T3 \\
\hline & & Cheng et al. 2017 & & \\
\hline
\end{tabular}

debriefing for meaningful learning (DML) as defined in Table 1. [8, 10-15, 23]. With the publication of the Promoting Excellence and Reflective Learning in Simulation (PEARLS) framework by Eppich and Cheng in 2015, scripted debriefing by healthcare educators can be applied for a variety of goals ranging from teaching the "right thing", to understanding team dynamics and cultural assumptions, with an eye towards both education and patient safety [12, 16-18]. All three elements are essential to ensure that learners are open to feedback, and that learning occurs.

\section{How Simulation Facilitates Learning}

The one-time standard medical pedagogy paradigm of "see one, do one, teach one" has not only proven less effective in training providers for infrequent but high-risk critical events, but has been shown to be impractical, expensive, and ultimately potentially unsafe [19]. Further, standardization and assessment of both skills and knowledge training can be difficult or impossible using this technique. Conversely, simulation can provide for an educational and training environment that is safe, low risk, standardized, and reproducible, with frequency of events readily controllable for use; so much so, that providing "on demand" simulation-based medical education (SBME) has been part of the Accreditation Council for Graduate Medical Education (ACGME) training of core competencies for over 10 years [20].

Learner engagement is a critical component of simulationbased learning. Simulation enables learner engagement in a psychologically safe environment through several approaches: active, hands-on learning in an immersive environment, opportunities for repetitive, deliberate practice, and facilitated feedback. Psychological safety in simulation gives the learner "permission" to make errors or perform inadequately without patient harm or judgment from participants $[21,22]$. Active, hands-on learning and emerging strategies to engagement such as gamification can be utilized to facilitate learner motivation [23, 24]. McKinnon et al. [25, 26] described early success with gamified learning to improve CPR practice frequency in a tertiary care children's hospital. Mastery learning, through deliberate practice of skill 
refinement with timely instructor feedback, is attainable before the task is done on a real patient [27]. One example of this is in improving chest compression performance. Several studies have demonstrated an improvement in chest compression psychomotor skills and resuscitation team performance utilizing the technique of "rapid cycle deliberate practice", where the learner is stopped and corrected once a learning need is identified. These components are all believed to improve adult learning and skills acquisition, especially when compared with passive learning techniques like didactic teaching [28, 29].

\section{Assessment and Evaluation}

Assessment of either a learner, a team, or the system is a key component to understanding the effectiveness of a simulationbased intervention. Simulation is typically used for formative assessments of skills and knowledge to provide feedback to improve learner performance and less commonly for summative or high-stakes evaluations for ensuring competency. Evaluators can capture specific time-limited metrics, such as time to start chest compressions for cardiac arrest, or observable critical actions such as use of closed-loop communication. In the past 5 years, a variety of qualitative and quantitative assessment tools have been validated, including those for resuscitation, team hand-offs, invasive procedures and neonatal intubation [30-33].

\section{Simulation Media and Clinical Fidelity}

Simulation "is a technique, not a technology" [34]. Consequently, simulation techniques have diversified for different modalities and settings in healthcare education. Broadly, simulation modalities can be divided into low and high-fidelity simulation. Fidelity is the measure to which the simulator or the simulation matches the real environment the scenario is attempting to recreate [35]. Low-fidelity simulation includes partial task and procedural trainers, designed to teach specific skills and/or techniques such as infant lumbar puncture, or central venous catheter placement. High-fidelity simulation provides a more immersive scenario by involving several dimensions of fidelity, such as functional, physical, and psychological fidelity (Table 1) [6, 36-39]. High-fidelity manikins may provide feedback to learners, such as lung sounds, verbal cues, and additional moulage as fits the scenario (Table 1) $[6,40]$. Standardized patients (SPs) may be used for one-on-one sessions to teach physical exam and communication skills acquisition, with directive feedback offered by the SP, facilitator, or both [41]. Both virtual and augmented reality (AR) simulations have the advantage of facilitating self-learning and feedback. Evidence of its efficacy, however, is only starting to emerge. Topics such as airway intubation, patient monitoring, and infant respiratory distress have been taught through this technique, with positive results [33, 42-46]. In the case of VR/AR simulations, feedback is given through a computer program; there is often no human instructor used for debriefing.

\section{Simulation Settings}

Choosing which setting to perform your simulation should be based upon your objectives and available resources. Simulation may be lab-based, in situ, mobile (where a laboratory is brought outside of the institution), or remotely accessed. Many institutions have "on site" simulation centers fully equipped for high fidelity simulation, with video recording capabilities, functioning patient rooms and operating rooms, and full body, computerized manikins or SPs [47]. Simulation centers are good for skill development and minimizing distractions but are costly to build and maintain. In contrast, in situ simulation may enhance the physical fidelity by bringing the experience to workplace teams in actual clinical environments [48]. The benefits of in situ simulation include greater access to providers, enhanced realism, as well as direct parallels and responses to patient care incidents, e.g., just-in-time training [49]. Finally, in situ simulation can allow for systems-based issues and latent safety threats to be discovered and addressed without harm to real patients [50, 51]. In situ simulation may also be made mobile with a simple cart, such as with rolling refreshers for CPR [52, 53]. Truly mobile simulation refers to the ability to take a simulator, or even a full simulation lab from one place to another such as in a vehicle. Finally, telesimulation has recently emerged as a viable method of teaching learners. Telesimulation occurs with either (1) one learner group remotely watching a simulation being performed by another group of learners and debriefing together, or (2) a remote instructor watching the learners and facilitating a debrief. This approach allows for extension of expensive and limited resources to help educate healthcare providers without access to traditional simulation [54, 55]. During the SARS-CoV-2 pandemic, due to constraints on social gatherings, telesimulation was used in some institutions $[56,57]$. Finally, a system's resources and limitations can inform the approach taken when considering which setting to use for simulation.

\section{Translating Simulation to PICU Care}

McGaghie and coauthors [58-60] proposed that just as translational science involves moving research discoveries from a basic science bench to the bedside, SBME research can be translated from the simulation lab to the clinical setting. The 
term "translational simulation" was introduced by Brazil in 2017 to describe the use of simulation to target improved patient safety and system-level outcomes, not necessarily involving educational interventions (Table 1) [61]. Figure 1 shows the different levels of translation as categorized by overall targeted outcomes, participants, and application to PCCM. The levels of translational outcomes follow: classroom or simulation laboratory (T1), moving downstream to improved and safer patient care practices and processes (T2), and ultimately to improved patient outcomes (T3). McGaghie et al. [28, 60] later added a fourth impact level to describe outcomes such as cost savings, skill retention, systemic educational value, and health care system improvements (T4). Examples of each of these are found in Fig. 1.

Below we discuss recent advances in simulation research within pediatric critical care medicine and how they can relate to improving different levels of outcomes. These simulations may be applied for education alone or for process improvement, and can focus on individuals, groups, groups of groups (such as interdisciplinary teams), or hospital systems.

\section{The Individual Learner}

SBME is a standard part of pediatric resident and fellow training, especially in the pediatric intensive care unit (PICU). Individual, learner-focused education may be used to teach both technical skills and nontechnical skills [18, 41, 52, 62]. Technical skills are improved by SBME on all translational levels.

For example, Johnson et al. [63] demonstrated a subjective improvement in nontechnical skills such as confidence and preparedness with a simulation-based course utilizing standardized patients for PCCM fellows for giving bad news
(T1). "Boot camps" provide focused training often during orientation and use deliberate practice to facilitate individual skill acquisition, such as advanced airway management, ultrasound guided central venous line placement, or chest tubes placement, as well as team training in crisis management principles and dynamics [64-66]. Individual technical skills such as CVL placement and thoracentesis are retained longer, and have fewer complications than those trained traditionally, thus demonstrating levels 3 and 4 translational outcomes (Table 2) [67-70].

In recent years, SBME has moved beyond the practitioner learner to also prepare patients, parents, and caregivers for ICU procedures or to transition between the ICU and their home [71]. Families of technology-dependent children exposed to simulation scenarios of tracheostomy-related emergencies reported increased confidence and preparedness to handle these situations at home, a T1 level outcome [71-73]. Virtual reality (VR), albeit a newer technology, has been used in several different ways for critically ill children. One promising use is for distraction during painful procedures such as burn dressing changes [74], lumbar punctures, and blood draws [75] which results in decreasing the amount of sedative or opiate required to complete the task (T3 level outcomes). Some preliminary studies have explored the association between VR and the ICU experience with results showing the potential for decreasing postintensive care syndrome, mitigating anxiety and delirium from prolonged hospitalizations [76], and encouraging early mobilization [77].

\section{Team-Based Learning}

Patient care in the PICU is inherently team based, thus simulation training goals tend to focus on development of intact
Fig. 1 Translational simulation framework and applications relevant to PCCM [58-60]

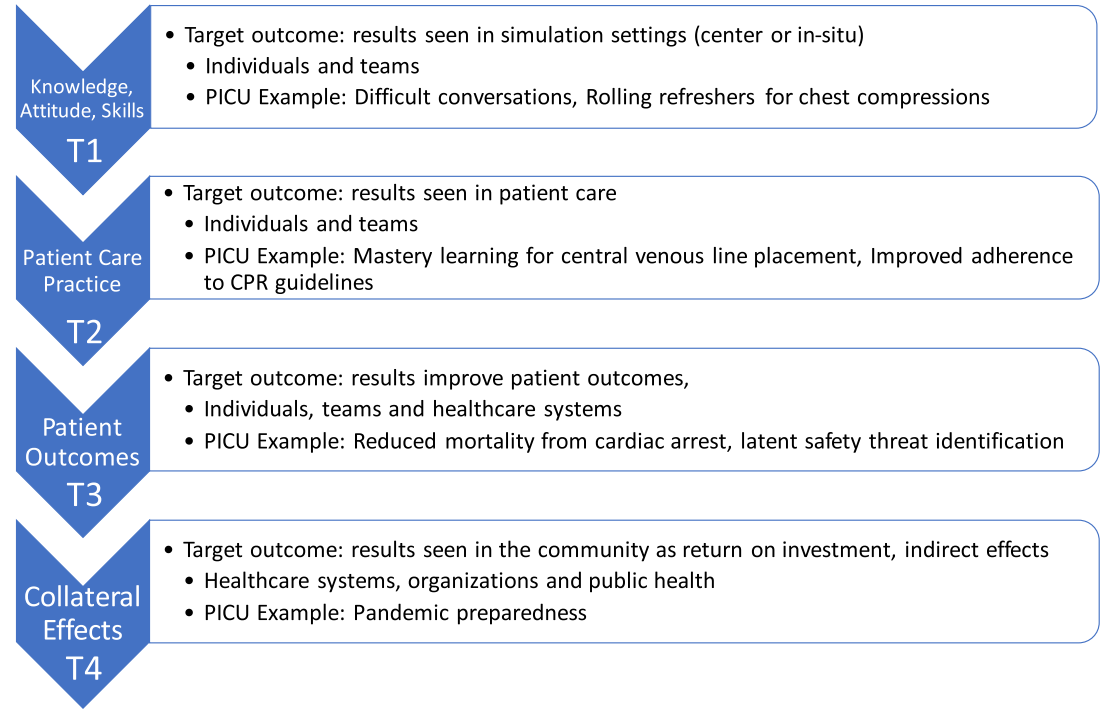


interprofessional teams and improvement of their approach to critical situations, problem-solving, process improvement, and questioning of cultural norms [18, 78]. Code-team simulations are a common focus of PCCM simulation, with several studies showing both technical skills improvement and improvement in team-dynamics [79-85].

Performance of in-hospital cardiopulmonary resuscitation has benefitted from using simulation to assess performance, refine processes, and improve team training in hopes of translating gains to real patient care [81, 82, 84, 85]. Hunt et al. [81] used simulation to develop, refine, and train with a "CPR Coach" role as part of a resuscitation quality bundle, which resulted in increased compliance with the American Heart Association's CPR guidelines during in hospital cardiac arrest, a T2 level outcome. Specific time-limited metrics, such as time to start chest compressions for cardiac arrest, and other critical actions can also be captured and used for performance evaluation and improvement [86]. Moreover, SBME for pediatric resuscitation has shown improvement in actual pediatric patients' survival rates of in-house arrest, translating to the patient-outcomes (T3) level [87].

\section{Interdisciplinary and Multiple Teams}

The management of a difficult pediatric airway, for example, typically involves several disciplines-PICU, anesthesiology and otolaryngology - who are not routinely educated together, yet often need to practice together posttraining. Lind et al. [88] developed a workshop to teach trainees from each of these subspecialties to work and communicate as a cohesive team-of-teams in order to successfully manage a deteriorating patient. The benefits of rehearsing in the real clinical environment and of using in-place medical equipment include providing a platform for testing how well healthcare sites and services will function as a system when faced with more complex challenges that cut across disciplines and department. Studies have shown simulating such processes as the activation of ECMO plans, can lead to process assessment and identification of latent safety threats, process improvement and refinement, and continual team training on these new processes [89, 90].

\section{Systems, Quality Improvement, and Patient Safety}

Simulation lends itself well as an investigative methodology into quality improvement and patient safety practices [91]. Dewan et al. [79] align simulation methodology with 5 key components of high reliability organizations: (1) preoccupation with failure, (2) reluctance to simplify, (3) commitment to resilience, and (4) sensitivity to operations, (5) deference to expertise. Even a simple simulation-based method to test new technology, such as different video laryngoscopy systems for intubation of Pierre Robin Sequence, prior to purchase or introduction into the patient care environment, may have broader implications for streamlining these processes [79]. Other applications of simulation for advancement of safe care include testing new clinical spaces prior to patient occupation or evaluating the preparedness of an existing space for a pediatric emergency or disaster such as Ebola or COVID-19 [79, 92]. Hospital-based simulation programs are partnering with patient safety experts to integrate simulation into the routine practices and structures of healthcare to fully leverage benefits at the systems level. Our own experience with entering simulation-discovered latent safety threats (LSTs) into our institution's safety event reporting system has resulted in process improvement and equipment changes [50].

Simulation provides the opportunity to probe a system for vulnerabilities and immediately debrief participants, thus allowing for learning from both success and failure while maintaining psychological safety. A standardized scenario of pediatric anaphylaxis performed in 28 international hospitals identified a high medication error rate, and the postevent debriefings revealed a common LST across institutions related to decision support aids [51]. Learning opportunities from these system-focused simulations can be maximized by using a specific debriefing framework such as PEARLS for system integration [16] which is based on Systems Engineering Initiative for Patient Safety (SEIPS) 2.0, a human-factors model of patient safety and the healthcare system [93].

Pandemic preparedness affords a particularly timely lens by which to illustrate the utility of simulation as a means to improving system-based care and incorporating this into routine practice. During the SARS-CoV-2 pandemic, simulation training was used on many levels for pandemic preparedness. For example, Ramanathan et al. described using simulation training on a team level in full PPE during provision of ECMO services during a pandemic [94-96]. Dieckmann et al. detailed how simulation might be used in the future to prepare for a pandemic response using simulation on several different scales to practice different coordinated responses. This may be on a team level, such as with intubations or simulated code events with the added complexity of donning and doffing PPE, or simulating process changes necessary to accommodate surge capacity within a hospital system. These simulations can allow debriefers to hone in on potential barriers to process implementation and to share good ideas that may arise.

\section{Research Networks}

As simulation research has moved away from answering the question "is simulation effective?" for educating healthcare 
workers and towards measuring patient level outcomes and other innovative uses, larger research collaboratives have shown benefits. The International Simulation Data Registry (ISDR) was created in 2014 to capture similar metrics to the AHA's Get with the Guidelines registry to compare simulation performance to real patient benchmark data [86]. The international simulation data registry (ISDR) allows for the assessment of mock codes by collecting such time-based data on simulated code events from multiple institutions in a similar manner to the American Heart Association's Get with the Guidelines registry (GWTG) which collects data on live patients [86]. Pediatrics has led the field of healthcare simulation with the creation of networks such as the International Network for Simulation-based Pediatric Innovation, Research and Education (INSPIRE). These registries and networks can facilitate the development of simulation-based multicenter collaborative research projects [97-99]. For example, the Improving Pediatric Acute Care Through Simulation (ImPACTS) program brings simulation to community hospitals to improve their preparedness to manage pediatric emergencies through combining education and assessment of the systems of care at these institutions $[53,100]$.

\section{Conclusions}

Throughout the past 5 years, the use of simulation has greatly expanded, broadening from simple task trainers and mock codes, to multidisciplinary, multifaceted simulations for teams of teams, to the use throughout hospital systems. Emerging technology has enabled a broader use of novel simulation techniques such as VR and telesimulation to expand access beyond large academic institutions.

Simulation is an exemplary educational model because it utilizes the principles of adult learning theory: involvement, experience, relevance, and problem centeredness [101]. It covers a broad swathe of learning topics and learner configurations, thus providing the flexibility needed to teach most adult learners. Simultaneously, simulation provides an ideal medium for understanding larger systems within the pediatric ICU through creation or recreation of vulnerable systems and processes. Simulation provides a modality by which the objectives of individual learning and systems testing converge towards the common goal of sustainably improving patient care.

Pediatric ICU simulation has been on the forefront of these changes, with PICU simulation research outcomes informing research into both other pediatric areas, as well as adult ICUs. Simulation has a tremendous capacity to effect change for the better by improving not only the knowledge base of our learners and the processes through which we work every day, but ultimately the care and lives of our patients.

\section{References}

Papers of particular interest, published recently, have been highlighted as:

- Of importance

- Of major importance

1. Gaba DM. The future vision of simulation in health care. Qual Saf Health Care. 2004;13(Suppl 1):i2-10. https://doi.org/10.1136/ qho.13.suppl_1.i2.

2. Denson JS, Abrahamson S. A computer-controlled patient simulator. JAMA. 1969;208(3):504-8.

3. Abrahamson S. Sim One-a patient simulator ahead of its time. Caduceus. 1997;13(2):29-41.

4. Abrahamson S, Denson JS, Wolf RM. Effectiveness of a simulator in training anesthesiology residents. J Med Educ. 1969;44(6): 515-9. https://doi.org/10.1097/00001888-196906000-00006.

5. Kohn LT, Corrigan J, Donaldson MS. To err is human: building a safer health system. DC: National academy press Washington; 2000.

6. Lioce L. Healthcare simulation dictionary. 2020.

7. Rutherford-Hemming T, Lioce L, Breymier T. Guidelines and essential elements for prebriefing. Simul Healthc. 2019;14(6): 409-14. https://doi.org/10.1097/SIH.0000000000000403.

8. Rudolph JW, Simon R, Raemer DB, Eppich WJ. Debriefing as formative assessment: closing performance gaps in medical education. Acad Emerg Med. 2008;15(11):1010-6. https://doi.org/10. 1111/j.1553-2712.2008.00248.x.

9. Issenberg SB, McGaghie WC, Petrusa ER, Lee Gordon D, Scalese RJ. Features and uses of high-fidelity medical simulations that lead to effective learning: a BEME systematic review. Med Teach. 2005;27(1):10-28. https://doi.org/10.1080/ 01421590500046924.

10. Dreifuerst KT. Using debriefing for meaningful learning to foster development of clinical reasoning in simulation. J Nurs Educ. 2012;51(6):326-33.

11. Rudolph JW, Simon R, Rivard P, Dufresne RL, Raemer DB. Debriefing with good judgment: combining rigorous feedback with genuine inquiry. Anesthesiol Clin. 2007;25(2):361-76. https://doi.org/10.1016/j.anclin.2007.03.007.

12. Eppich W, Cheng A. Promoting Excellence and Reflective Learning in Simulation (PEARLS): development and rationale for a blended approach to health care simulation debriefing. Simul Healthc. 2015;10(2):106-15. https://doi.org/10.1097/SIH. 0000000000000072.

13. Raemer D, Anderson M, Cheng A, Fanning R, Nadkarni V, Savoldelli G. Research regarding debriefing as part of the learning process. Simul Healthc. 2011;6(Suppl):S52-7. https://doi.org/10. 1097/SIH.0b013e31822724d0.

14. Cantrell MA. The importance of debriefing in clinical simulations. Clinical Simulation in Nursing. 2008;4(2):e19-23. https://doi.org/ 10.1016/j.ecns.2008.06.006.

15. Sawyer T, Eppich W, Brett-Fleegler M, Grant V, Cheng A. More than one way to debrief: a critical review of healthcare simulation debriefing methods. Simul Healthc. 2016;11(3):209-17. https:// doi.org/10.1097/SIH.0000000000000148.

16. Dube MM, Reid J, Kaba A, Cheng A, Eppich W, Grant V, et al. PEARLS for systems integration: a modified PEARLS framework for debriefing systems-focused simulations. Simul Healthc. 2019;14(5):333-42. https://doi.org/10.1097/SIH. 0000000000000381.

17. Bajaj K, Meguerdichian M, Thoma B, Huang S, Eppich W, Cheng A. The PEARLS healthcare debriefing tool. Acad Med. 
2018;93(2):336. https://doi.org/10.1097/ACM. 0000000000002035.

18. Roussin CJ, Weinstock P. SimZones: an organizational innovation for simulation programs and centers. Acad Med. 2017;92(8): 1114-20. https://doi.org/10.1097/ACM.0000000000001746.

19. Dunn WF. Simulators in critical care education and beyond. In: Society of Critical Care Medicine; 2004.

20. Lopreiato JO, Sawyer T. Simulation-based medical education in pediatrics. Acad Pediatr. 2015;15(2):134-42. https://doi.org/10. 1016/j.acap.2014.10.010.

21. Rudolph JW, Raemer DB, Simon R. Establishing a safe container for learning in simulation: the role of the presimulation briefing. Simul Healthc. 2014;9(6):339-49. https://doi.org/10.1097/SIH. 0000000000000047.

22. Roussin CJ, MacLean TL, Rudolph JW. The safety in unsafe teams: a multilevel approach to team psychological safety. J Manag. 2016;42(6):1409-33. https://doi.org/10.1177/ 0149206314525204.

23. Harwayne-Gidansky I, Balmer DF, Doughty CB, Scarlatos LL, Chang T, Song JL, et al. A qualitative analysis of resident motivation. Simul Gaming. 2020;0(0):1046878120913597. Artn 1046878120913597 . https://doi.org/10.1177/ 1046878120913597.

24. Rutledge C, Walsh CM, Swinger N, Auerbach M, Castro D, Dewan M, et al. Gamification in action: theoretical and practical considerations for medical educators. Acad Med. 2018;93(7): 1014-20. https://doi.org/10.1097/ACM.0000000000002183.

25. MacKinnon RJ, Stoeter R, Doherty C, Fullwood C, Cheng A, Nadkarni V, et al. Self-motivated learning with gamification improves infant CPR performance, a randomised controlled trial. BMJ Simulat Technol Enhanced Learn. 2015;1(3):71-6. https:// doi.org/10.1136/bmjstel-2015-000061.

26. Chang TP, Raymond T, Dewan M, MacKinnon R, Whitfill T, Harwayne-Gidansky I, Doughty C, Frisell K, Kessler D, Wolfe H, Auerbach M, Rutledge C, Mitchell D, Jani P, Walsh CM, INSPIRE In-Hospital QCPR Leaderboard Investigators. The effect of an international competitive leaderboard on self-motivated simulation-based CPR practice among healthcare professionals: A randomized control trial. Resuscitation. 2019;138:273-81. https:// doi.org/10.1016/j.resuscitation.2019.02.050.

27. Ericsson KA. Deliberate practice and acquisition of expert performance: a general overview. Acad Emerg Med. 2008;15(11):98894. https://doi.org/10.1111/j.1553-2712.2008.00227.x.

28. McGaghie WC, Issenberg SB, Petrusa ER, Scalese RJ. Revisiting 'a critical review of simulation-based medical education research: 2003-2009. Med Educ. 2016;50(10):986-91. https://doi.org/10. 1111/medu.12795.

29. McGaghie WC, Issenberg SB, Cohen ER, Barsuk JH, Wayne DB. Does simulation-based medical education with deliberate practice yield better results than traditional clinical education? A metaanalytic comparative review of the evidence. Acad Med. 2011;86(6):706-11. https://doi.org/10.1097/ACM. 0b013e318217e119.

30. Brett-Fleegler MB, Vinci RJ, Weiner DL, Harris SK, Shih MC, Kleinman ME. A simulator-based tool that assesses pediatric resident resuscitation competency. Pediatrics. 2008;121(3):e597603. https://doi.org/10.1542/peds.2005-1259.

31. Davis J, Roach C, Elliott C, Mardis M, Justice EM, Riesenberg LA. Feedback and assessment tools for handoffs: a systematic review. J Grad Med Educ. 2017;9(1):18-32. https://doi.org/10. 4300/JGME-D-16-00168.1.

32. Faudeux C, Tran A, Dupont A, Desmontils J, Montaudie I, Breaud $\mathrm{J}$ et al. Development of reliable and validated tools to evaluate technical resuscitation skills in a pediatric simulation setting: resuscitation and emergency simulation checklist for assessment in pediatrics. J Pediatr 2017;188:252-7 e6. https://doi.org/10.1016/j. jpeds.2017.03.055.

33. Johnston L, Sawyer T, Nishisaki A, Whitfill T, Ades A, French H, et al. INSPIRE Research Network. Neonatal intubation competency assessment tool: development and validation. Acad Pediatr. 2019;19(2):157-64. https://doi.org/10.1016/j.acap.2018.07.008.

34. Gaba DM. The future vision of simulation in health care. BMJ Qual Saf. 2004;13(suppl 1):i2-i10.

35. Maran NJ, Glavin RJ. Low- to high-fidelity simulation - a continuum of medical education? Med Educ. 2003;37(Suppl 1):22-8 https://doi.org/10.1046/j.1365-2923.37.s1.9.x.

36. Wilson L, CPAN C, CHSE C-A, Wittmann-Price RA. Review manual for the Certified Healthcare Simulation Educator exam: Springer Publishing Company; 2018.

37. Alexander AL, Brunyé T, Sidman J, Weil SA. From gaming to training: a review of studies on fidelity, immersion, presence, and buy-in and their effects on transfer in pc-based simulations and games. DARWARS Training Impact Group. 2005;5:1-14.

38. McGaghie WC. Mastery learning: it is time for medical education to join the 21st century. Acad Med. 2015;90(11):1438-41. https:// doi.org/10.1097/ACM.0000000000000911.

39. Dieckmann P, Rall M. Designing a scenario as a simulated clinical experience: the TUPASS scenario script. Clinical simulation: Operations, engineering, and management. 2008:541-50.

40. Levine AI, DeMaria S Jr, Schwartz AD, Sim AJ. The comprehensive textbook of healthcare simulation: Springer Science \& Business Media; 2013.

41. Johnson EM, Hamilton MF, Watson RS, Claxton R, Barnett M, Thompson AE, et al. An intensive, simulation-based communication course for pediatric critical care medicine (PCCM) fellows. Pediatric Crit Care Med. 2017;18(8):e348 e355.

42. Zackoff MW, Real FJ, Abramson EL, Li ST, Klein MD, Gusic ME. Enhancing educational scholarship through conceptual frameworks: a challenge and roadmap for medical educators. Acad Pediatr. 2019;19(2):135-41. https://doi.org/10.1016/j.acap. 2018.08.003.

43. Zackoff MW, Klein M, Real F, Guiot AB, Lehmann C, Tegtmeyer $\mathrm{K}$. Impact of an immersive virtual reality curriculum to improve medical student clinical assessment of infants with respiratory distress. Am Acad Pediatr. 2019.

44. Slamon N, Agasthya N. 1057: virtual reality simulation for pediatric airway intubation training. Crit Care Med. 2020;48(1):508.

45. Teng C-C, Redfearn B, Nuttall C, Jarvis S, Carr J, Jensen J et al., editors. Mixed reality patients monitoring application for critical care nurses. Proceedings of the third International Conference on Medical and Health Informatics 2019; 2019.

46. Zackoff MW, Real FJ, Sahay RD, Fei L, Guiot A, Lehmann C, et al. Impact of an immersive virtual reality curriculum on medical students' clinical assessment of infants with respiratory distress. Pediatr Crit Care Med. 2020;21:477, 485. https://doi.org/10.1097/ PCC.0000000000002249.

47. Weinstock PH, Kappus LJ, Kleinman ME, Grenier B, Hickey P, Burns JP. Toward a new paradigm in hospital-based pediatric education: the development of an onsite simulator program. Pediatr Crit Care Med. 2005;6(6):635-41. https://doi.org/10. 1097/01.pcc.0000185489.07469.af.

48. Weinstock PH, Kappus LJ, Garden A, Burns JP. Simulation at the point of care: reduced-cost, in situ training via a mobile cart. Pediatr Crit Care Me. 2009;10(2):176-81.

49. Sam J, Pierse M, Al-Qahtani A, Cheng A. Implementation and evaluation of a simulation curriculum for paediatric residency programs including just-in-time in situ mock codes. Paediatr Child Health. 2012;17(2):e16-20. https://doi.org/10.1093/pch/17.2.e16.

50. Harwayne-Gidansky I, Culver K, Cavanaugh S, Panesar R. Using mirror patients to enhance patient safety. Simul Healthc. 
2019;14(3):195-200. https://doi.org/10.1097/SIH. 0000000000000348 .

51. Maa T, Scherzer DJ, Harwayne-Gidansky I, Capua T, Kessler DO, Trainor JL, et al. Prevalence of errors in anaphylaxis in kids (PEAK): a multicenter simulation-based study. J Allergy Clin Immunol Pract. 2020;8(4):1239-46 e3. https://doi.org/10.1016/j. jaip.2019.11.013.

52. Niles DE, Nishisaki A, Sutton RM, Elci OU, Meaney PA, O'Connor KA, et al. Improved retention of chest compression psychomotor skills with brief "rolling refresher" training. Simul Healthc. 2017;12(4):213-9. https://doi.org/10.1097/SIH. 0000000000000228 .

53. Walsh BM, Auerbach MA, Gawel MN, Brown LL, Byrne BJ, Calhoun A, et al. Community-based in situ simulation: bringing simulation to the masses. Adv Simul (Lond). 2019;4(1):30. https:// doi.org/10.1186/s41077-019-0112-y.

54. Hayden EM, Khatri A, Kelly HR, Yager PH, Salazar GM. Mannequin-based telesimulation: increasing access to simulation-based education. Acad Emerg Med. 2018;25(2):1447. https://doi.org/10.1111/acem.13299.

55. Butler L, Whitfill T, Wong AH, Gawel M, Crispino L, Auerbach $\mathrm{M}$. The impact of telemedicine on teamwork and workload in pediatric resuscitation: a simulation-based, randomized controlled study. Telemed J E Health. 2019;25(3):205-12. https://doi.org/10. 1089/tmj.2018.0017.

56. Naik N, Finkelstein RA, Howell J, Rajwani K, Ching K. Telesimulation for COVID-19 ventilator management training with social-distancing restrictions during the coronavirus pandemic. Simul Gaming. 2020;51(4):571-7. https://doi.org/10.1177/ 1046878120926561.

57. Balmaks R, Auzina L, Gross IT. Remote rapid cycle deliberate practice simulation training during the COVID-19 pandemic. BMJ Simulation and Technology Enhanced Learning. 2020. https://doi.org/10.1136/bmjstel-2020-000671.

58. McGaghie WC. Medical education research as translational science. Sci Transl Med. 2010;2(19):19cm8. https://doi.org/10.1126/ scitranslmed.3000679.

59. Griswold-Theodorson S, Ponnuru S, Dong C, Szyld D, Reed T, McGaghie WC. Beyond the simulation laboratory: a realist synthesis review of clinical outcomes of simulation-based mastery learning. Acad Med. 2015;90(11):1553-60. https://doi.org/10. 1097/ACM.0000000000000938.

60. McGaghie WC, Draycott TJ, Dunn WF, Lopez CM, Stefanidis D. Evaluating the impact of simulation on translational patient outcomes. Simul Healthc. 2011;6(Suppl):S42-7. https://doi.org/10. 1097/SIH.0b013e318222fde9.

61. Brazil V. Translational simulation: not 'where?' but 'why?' A functional view of in situ simulation. Adv Simul (Lond). 2017;2: 20. https://doi.org/10.1186/s41077-017-0052-3.

62. Kessler D, Pusic M, Chang TP, Fein DM, Grossman D, Mehta R, et al. For the INSPIRE LP investigators Impact of just-in-time and just-in-place simulation on intern success with infant lumbar puncture. Pediatrics. 2015;135(5):e1237-46. https://doi.org/10.1542/ peds.2014-1911.

63. Johnson EM, Hamilton MF, Watson RS, Claxton R, Barnett M, Thompson AE, et al. An intensive, simulation-based communication course for pediatric critical care medicine fellows. Pediatr Crit Care Med. 2017;18(8):e348-e55. https://doi.org/10.1097/PCC. 0000000000001241.

64. Fernandez GL, Page DW, Coe NP, Lee PC, Patterson LA, Skylizard L, et al. Boot cAMP: educational outcomes after 4 successive years of preparatory simulation-based training at onset of internship. J Surg Educ. 2012;69(2):242-8.

65. Nishisaki A, Hales R, Biagas K, Cheifetz I, Corriveau C, Garber $\mathrm{N}$, et al. A multi-institutional high-fidelity simulation "boot camp" orientation and training program for first year pediatric critical care fellows. Pediatr Crit Care Med. 2009;10(2):157-62. https://doi. org/10.1097/PCC.0b013e3181956d29.

66. Cohen ER, Barsuk JH, Moazed F, Caprio T, Didwania A, McGaghie WC, et al. Making July safer: simulation-based mastery learning during intern boot camp. Acad Med. 2013;88(2): 233-9. https://doi.org/10.1097/ACM.0b013e31827bfc0a.

67. Barsuk JH, Cohen ER, Williams MV, Scher J, Jones SF, Feinglass $\mathrm{J}$, et al. Simulation-based mastery learning for thoracentesis skills improves patient outcomes: a randomized trial. Acad Med. 2018;93(5):729-35. https://doi.org/10.1097/ACM. 0000000000001965 .

68. Barsuk JH, Cohen ER, McGaghie WC, Wayne DB. Long-term retention of central venous catheter insertion skills after simulation-based mastery learning. Acad Med. 2010;85(10 Suppl):S9-12. https://doi.org/10.1097/ACM.0b013e3181ed436c.

69. Cohen ER, Feinglass J, Barsuk JH, Barnard C, O'Donnell A, McGaghie WC, et al. Cost savings from reduced catheter-related bloodstream infection after simulation-based education for residents in a medical intensive care unit. Simul Healthc. 2010;5(2): 98-102. https://doi.org/10.1097/SIH.0b013e3181bc8304.

70. Barsuk JH, McGaghie WC, Cohen ER, O'Leary KJ, Wayne DB. Simulation-based mastery learning reduces complications during central venous catheter insertion in a medical intensive care unit. Crit Care Med. 2009;37(10):2697-701.

71. Graham RJ, Amar-Dolan LR, Roussin CJ, Weinstock PH. Bridging the stressful gap between ICU and home: medical simulation for pediatric patients and their families. Pediatr Crit Care Me. 2019;20(4):e221-e4.

72. Prickett K, Deshpande A, Paschal H, Simon D, Hebbar KB. Simulation-based education to improve emergency management skills in caregivers of tracheostomy patients. Int J Pediatr Otorhinolaryngol. 2019;120:157-61. https://doi.org/10.1016/j. ijporl.2019.01.020.

73. Tofil NM, Schier S, Benningfield B, Cooper A, Sloane PA, Zinkan L, et al. Tracheostomy education for parents utilizing simulation: a new paradigm in parental. education. 2018.

74. Hoffman HG, Rodriguez RA, Gonzalez M, Bernardy M, Pena R, Beck W, et al. Immersive virtual reality as an adjunctive nonopioid analgesic for pre-dominantly Latin American children with large severe burn wounds during burn wound cleaning in the intensive care unit: a pilot study. Front Hum Neurosci. 2019;13(262). https://doi.org/10.3389/fnhum.2019.00262.

75. Gold JI, Mahrer NE. Is virtual reality ready for prime time in the medical space? A randomized control trial of pediatric virtual reality for acute procedural pain management. J Pediatr Psychol. 2018;43(3):266-75. https://doi.org/10.1093/jpepsy/jsx129.

76. Badke CM, Essner BS, O'Connell M, Malakooti MR. An innovative virtual reality experience in the PICU: a pilot study. Pediatr Crit Care Med. 2019;20(6):e283-e6. https://doi.org/10.1097/ PCC.0000000000001917.

77. Wang J, Zhang C, Jia Y, Shi C, Choi T, Xiao Q. Development of a virtual reality system for early mobilization of critically ill patients. Stud Health Technol Inform. 2019;264:1805-6. https://doi.org/ 10.3233/SHTI190657.

78. Colman N, Figueroa J, McCracken C, Hebbar KB. Can simulation based-team training impact bedside teamwork in a pediatric intensive care unit? J Pediatr Intensive Care. 2019;8(4):195-203. https://doi.org/10.1055/s-0039-1688928.

79. Dewan M, Tegtmeyer K. Let's get it right, set it up again: achieving high reliability through simulation and debriefing. Pediatr Crit Care Med. 2019;20(5):497-9. https://doi.org/10.1097/Pcc. 0000000000001908 .

80. Cory MJ, Colman N, McCracken CE, Hebbar KB. Rapid cycle deliberate practice versus reflective debriefing for pediatric septic shock training. Pediatr Crit Care Med. 2019;20(5):481-9. https:// doi.org/10.1097/PCC.0000000000001891. 
81. Hunt EA, Jeffers J, McNamara L, Newton H, Ford K, Bernier M, et al. Improved cardiopulmonary resuscitation performance with CODE ACES(2): a resuscitation quality bundle. J Am Heart Assoc. 2018;7(24):e009860. https://doi.org/10.1161/JAHA.118. 009860.

82. Chancey RJ, Sampayo EM, Lemke DS, Doughty CB. Learners' experiences during rapid cycle deliberate practice simulations: a qualitative analysis. Simul Healthc. 2019;14(1):18-28. https://doi. org/10.1097/SIH.0000000000000324.

83. Cheng A, Brown LL, Duff JP, Davidson J, Overly F, Tofil NM, Peterson DT, White ML, Bhanji F, Bank I, Gottesman R, Adler M, Zhong J, Grant V, Grant DJ, Sudikoff SN, Marohn K, Charnovich A, Hunt EA, Kessler DO, Wong H, Robertson N, Lin Y, Doan Q, Duval-Arnould JM, Nadkarni VM Improving cardiopulmonary resuscitation with a CPR feedback device and refresher simulations (CPR CARES Study): a randomized clinical trial. JAMA Pediatr 2015;169(2):137-144. https://doi.org/10.1001/ jamapediatrics.2014.2616.

84. Cheng A, Duff JP, Kessler D, Tofil NM, Davidson J, Lin Y, et al. Optimizing CPR performance with CPR coaching for pediatric cardiac arrest: a randomized simulation-based clinical trial. Resuscitation. 2018;(Circulation 13218 Suppl. 2 2015):132, 3340. https://doi.org/10.1016/j.resuscitation.2018.08.021.

85. Cheng A, Kessler D, Lin Y, Tofil NM, Hunt EA, Davidson J, et al. International Network for Simulation-based Pediatric Innovation, Research and Education (INSPIRE) CPR Investigators. Influence of cardiopulmonary resuscitation coaching and provider role on perception of cardiopulmonary resuscitation quality during simulated pediatric cardiac arrest. Pediatr Crit Care Med. 2019;20(4): e191-e8. https://doi.org/10.1097/PCC.0000000000001871.

86. Calhoun AW, Nadkarni V, Venegas-Borsellino C, White ML, Kurrek M. Concepts for the simulation community: development of the international simulation data registry. Simul Healthc. 2018;13(6):427-34. https://doi.org/10.1097/SIH. 0000000000000311

87. Andreatta P, Saxton E, Thompson M, Annich G. Simulationbased mock codes significantly correlate with improved pediatric patient cardiopulmonary arrest survival rates. Pediatr Crit Care Med. 2011;12(1):33-8. https://doi.org/10.1097/PCC. 0b013e3181e89270.

88. Lind MM, Corridore M, Sheehan C, Moore-Clingenpeel M, Maa T. A multidisciplinary approach to a pediatric difficult airway simulation course. Otolaryngol Head Neck Surg. 2018;159(1): 127-35. https://doi.org/10.1177/0194599818758993.

89. Sawyer T, Burke C, McMullan DM, Chan T, Valdivia H, Yalon L, et al. Impacts of a pediatric extracorporeal cardiopulmonary resuscitation (ECPR) simulation training program. Acad Pediatr. 2019;19(5):566-71. https://doi.org/10.1016/j.acap.2019.01.005.

90. Di Nardo M, David P, Stoppa F, Lorusso R, Raponi M, Amodeo A, et al. The introduction of a high-fidelity simulation program for training pediatric critical care personnel reduces the times to manage extracorporeal membrane oxygenation emergencies and improves teamwork. J Thorac Dis. 2018;10(6):3409-17. https://doi. org/10.21037/jtd.2018.05.77.
91. Cheng A, Grant V, Auerbach M. Using simulation to improve patient safety: dawn of a new era. JAMA Pediatr. 2015;169(5): 419-20. https://doi.org/10.1001/jamapediatrics.2014.3817.

92. Biddell EA, Vandersall BL, Bailes SA, Estephan SA, Ferrara LA, Nagy KM, O'Connell JL, Patterson MD Use of simulation to gauge preparedness for Ebola at a free-standing children's hospital. Simul Healthc 2016;11(2):94-99. https://doi.org/10.1097/ SIH.0000000000000134.

93. Holden RJ, Carayon P, Gurses AP, Hoonakker P, Hundt AS, Ozok AA, et al. SEIPS 2.0: a human factors framework for studying and improving the work of healthcare professionals and patients. Ergonomics. 2013;56(11):1669-86. https://doi.org/10. 1080/00140139.2013.838643.

94. Ramanathan K, Antognini D, Combes A, Paden M, Zakhary B, Ogino $\mathrm{M}$, et al. Planning and provision of ECMO services for severe ARDS during the COVID-19 pandemic and other outbreaks of emerging infectious diseases. Lancet Respir Med. 2020;8:518, 526. https://doi.org/10.1016/s2213-2600(20)301211 .

95. Dieckmann P, Torgeirsen K, Qvindesland SA, Thomas L, Bushell $\mathrm{V}$, Langli Ersdal H. The use of simulation to prepare and improve responses to infectious disease outbreaks like COVID-19: practical tips and resources from Norway, Denmark, and the UK. Adv Simul. 2020;5(1). https://doi.org/10.1186/s41077-020-00121-5.

96. Brewster DJ, Chrimes NC, Do TB, Fraser K, Groombridge CJ, Higgs A, et al. Consensus statement: Safe Airway Society principles of airway management and tracheal intubation specific to the COVID-19 adult patient group. Med J Aust. 2020;16.

97. Cheng A, Auerbach M, Calhoun A, Mackinnon R, Chang TP, Nadkarni V, et al. Building a community of practice for researchers: the international network for simulation-based pediatric innovation, research and education. Simul Healthc. 2018;13(3S Suppl 1):S28-34. https://doi.org/10.1097/SIH. 0000000000000269 .

98. Cheng A, Kessler D, Mackinnon R, Chang TP, Nadkarni VM, Hunt EA, Duval-Arnould J, Lin Y, Pusic M, Auerbach M Conducting multicenter research in healthcare simulation: lessons learned from the INSPIRE network. Adv Simul (Lond) 2017;2(1): 6. https://doi.org/10.1186/s41077-017-0039-0.

99. Whitfill T, Gross IT, Auerbach M. Establishing and maintaining multicenter studies in healthcare simulation research. In: Healthcare Simulation Research: Springer; 2019. p. 285-93.

100. Whitfill TM, Remick KE, Olson LM, Richards R, Brown KM, Auerbach MA, et al. Statewide pediatric facility recognition programs and their association with pediatric readiness in emergency departments in the United States. J Pediatr. 2020;218:210-6 e2. https://doi.org/10.1016/j.jpeds.2019.10.017.

101. Knowles MS. The adult learner: a neglected species. In: Building blocks of human potential series. 3rd ed. Houston: Gulf Pub. Co., Book Division; 1984.

Publisher's Note Springer Nature remains neutral with regard to jurisdictional claims in published maps and institutional affiliations. 